\title{
Incorporating the principles of the patient- centered medical home into a student-run free clinic
}

This article was published in the following Dove Press journal:

Advances in Medical Education and Practice

II September 2014

Number of times this article has been viewed

\author{
Megan C Riddle ${ }^{1, *}$ \\ Jiahui $\operatorname{Lin}^{3, *}$ \\ Jonathan B Steinman² \\ Joshua D Salvi² \\ Margaret M Reynolds ${ }^{3}$ \\ Anne S Kastor ${ }^{3, \dagger}$ \\ Christina Harris ${ }^{4}$ \\ Carla Boutin-Foster ${ }^{3}$ \\ 'Department of Psychiatry and \\ Behavioral Sciences, University \\ of Washington, ${ }^{2}$ Weill Cornell/ \\ Rockefeller/Sloan-Kettering Tri- \\ Institutional MD-PhD Program, \\ ${ }^{3}$ Department of Internal Medicine, \\ Weill Cornell Medical College, New \\ York, NY, ${ }^{4}$ Department of Medicine, \\ Division of General Internal Medicine, \\ VA Greater Los Angeles Healthcare \\ System, David Geffen School of \\ Medicine at UCLA, LA, USA \\ *These authors contributed equally \\ to this work \\ ${ }^{\dagger}$ Anne S Kastor passed away on July 5 , \\ 2013.
}

\begin{abstract}
As the health care delivery landscape changes, medical schools must develop creative strategies for preparing future physicians to provide quality care in this new environment. Despite the growing prominence of the patient-centered medical home (PCMH) as an effective model for health care delivery, few medical schools have integrated formal education on the PCMH into their curricula. Incorporating the PCMH model into medical school curricula is important to ensure that students have a comprehensive understanding of the different models of health care delivery and can operate effectively as physicians. The authors provide a detailed description of the process by which the Weill Cornell Community Clinic (WCCC), a student-run free clinic, has integrated PCMH principles into a service-learning initiative. The authors assessed patient demographics, diagnoses, and satisfaction along with student satisfaction. During the year after a PCMH model was adopted, 112 students and 19 licensed physicians volunteered their time. A review of the 174 patients seen from July 2011 to June 2012 found that the most common medical reasons for visits included management of hypertension, hyperlipidemia, diabetes, gastrointestinal conditions, arthritis, anxiety, and depression. During the year after the adoption of the PCMH model, $87 \%$ were very or extremely satisfied with their care, and $96 \%$ of the patients would recommend the WCCC to others. Students who participate in the WCCC gain hands-on experience in coordinating care, providing continuity of care, addressing issues of accessibility, and developing quality and safety metrics. The WCCC experience provides an integrative model that links service-learning with education on health care delivery in a primary care setting. The authors propose that adoption of this approach by other student-run clinics provides a substantial opportunity to improve medical education nationwide and better prepare future physicians to practice within this new model of health care delivery.
\end{abstract}

Keywords: medical education, patient-centered medical home, medical students, servicelearning, student-run free clinic.

\section{Introduction}

In 2010, the Carnegie Foundation made recommendations to fundamentally change medical education. ${ }^{1}$ It called for curricular reforms that would provide earlier exposure to clinical work, more hands-on experiential learning, and a greater focus on care coordination and working with interprofessional teams. The call for medical education reform parallels the call for health care reform. Medical schools must make certain that efforts toward curricular reform align with the rapidly changing health care delivery system.

As the health care delivery landscape changes, medical schools must develop creative strategies for preparing future physicians to provide quality care in this new environment. One such change is the increasing adoption of the patient-centered 
medical home (PCMH). The PCMH promises to deliver care that is more accessible, effective, efficient, and safe, while simultaneously bending the cost curve. ${ }^{2}$ The core tenets of the PCMH are a personal physician, a physician-directed medical practice, a whole-person orientation, integration and coordination of care, quality and safety assurance, enhanced access, and outcome-based payment. ${ }^{3}$ As health centers across the country adopt this model of care, future physicians need to be prepared to incorporate these principles in their practices.

Despite the growing prominence of the PCMH as effective models for health care delivery, few medical schools have integrated formal education on the PCMH into their curricula. Studies show that few medical students are exposed to this model in their formal education or have opportunities to gain hands-on experience using this model of care. ${ }^{4-6}$ Only $41 \%$ of family medicine departments in one survey reported implementing a PCMH curriculum for students, and teaching modalities largely focused on educational conferences rather than longitudinal exposure. ${ }^{5}$ Integrating the tenets of the PCMH into medical school curricula is important to ensure that students have a comprehensive understanding of the different models of health care delivery and can operate effectively as physicians.

Student-run free clinics have gained popularity as a unique experiential learning opportunity that provides hands-on experience for students while serving as a safety net for medically underserved and uninsured populations. Approximately 110 student-run free clinics exist in the US. ${ }^{7}$ They are operated by health professional students under the supervision of a licensed clinician and provide care to medically uninsured populations. ${ }^{7,8}$ Free clinics place students as early as their first year of medical school on the front lines of problem solving and care coordination for patients who have no or little access to care. ${ }^{7}$ The infrastructure of these clinics varies, with students seeing patients after hours in an established care facility or in community-based settings, such as mobile health clinics, shelters, or churches. ${ }^{9}$ There is literature to support that patients receive quality care at these student-run clinics and are generally satisfied with the experience. ${ }^{10}$ These patients most commonly present to these clinics requesting acute care, chronic disease management, screenings, or social services. However, a notable absence exists in the literature regarding how student-run clinics can be used to expose students to new systems of health care delivery, such as the PCMH.

The PCMH model is particularly applicable to the care of patients who are economically and medically underserved.
The lack of health insurance and basic necessities often renders this population vulnerable to discontinuous or fragmented care. A PCMH model can help to provide continuous and patient-centric care that addresses social determinants of health through linkages with key community agencies. ${ }^{11}$ Therefore, students who care for the underserved in a free clinic setting should be aware of this model.

Given the limited exposure to the PCMH within current curricula, new physicians may be ill-prepared to practice within a PCMH model of care. ${ }^{5}$ Integrating the PCMH model into the medical school curriculum would allow students to learn how to establish long-term relationships with patients, work in interprofessional teams, integrate methods of quality assurance and patient safety into practice, and develop proficiency in the use of electronic health records (EHRs). ${ }^{12}$ The objective of this paper is to provide a detailed description of the processes by which the Weill Cornell Community Clinic (WCCC, New York, NY, USA), a student-run free clinic, adopted elements of the PCMH model into an existing experiential learning program.

\section{Methods \\ Description of the WCCC}

The WCCC was established by medical students in 2003 with the mission of providing care to patients who were uninsured or had insufficient health insurance to cover the cost of care. The activities of the clinic are coordinated by a board of medical students working closely with volunteer physicians and a Faculty Medical Director. Each board member is responsible for specific tasks, such as scheduling patient visits, directing patient care, and coordinating psychosocial screenings and services. At the student level, two Clinical Directors and two Executive Directors oversee the board. Clinical Directors are fourth year medical students who serve a 1-year term and supervise the care of all patients (Table 1). Executive Directors are two MD-PhD students during their graduate training who deal with administrative tasks of the WCCC. The board also operates under the close supervision of a Faculty Medical Director, a physician who provides overall guidance for the program, ensures that patients are provided with quality care, and encourages students to participate as active learners. The Faculty Medical Director was selected by the Dean's office as a faculty member who has practiced in primary care with experience supervising and teaching students. In order to ensure support for this position, the Faculty Medical Director receives 0.1 full time equivalents for her work with the WCCC. The WCCC operates on a $\$ 50,000$ annual budget funded by a combination of monetary 
Table I Student and faculty positions at the Weill Cornell Community Clinic (New York, NY, USA)

\begin{tabular}{|c|c|c|c|}
\hline Title & Qualifications & Description & $\begin{array}{l}\text { Minimum } \\
\text { commitment }\end{array}$ \\
\hline Clinical Directors & $\begin{array}{l}\text { Two third to fourth year } \\
\text { medical students }\end{array}$ & $\begin{array}{l}\text { - Monitor all patient care through close interactions with } \\
\text { Senior Clinicians } \\
\text { - Handle long-term patient follow-up } \\
\text { - Meet weekly with Faculty Medical Director to discuss } \\
\text { patient care } \\
\text { - Conduct board meetings }\end{array}$ & I year \\
\hline Executive Directors & $\begin{array}{l}\text { Two MD-PhD students in } \\
\text { graduate school }\end{array}$ & $\begin{array}{l}\text { - Work with Clinical Directors to set clinic protocols and } \\
\text { policies } \\
\text { - Manage budgeting and fundraising } \\
\text { - Conduct board meetings }\end{array}$ & $2-3$ years \\
\hline Faculty Medical Director & One faculty physician & $\begin{array}{l}\text { - Meet regularly with Clinical Directors to discuss patient care } \\
\text { - Provide guidance on patient issues that arise between clinic } \\
\text { sessions }\end{array}$ & Open-ended \\
\hline Board & $\begin{array}{l}20+\text { medical students - most } \\
\text { are first or second year }\end{array}$ & $\begin{array}{l}\text { Roles include patient scheduling, social work coordination, } \\
\text { insurance screening, quality assurance, data management, } \\
\text { and information technology } \\
\text { - Attend board meetings to review all patients seen at most } \\
\text { recent clinic, address ongoing issues, and resolve clinic } \\
\text { matters smoothly and efficiently }\end{array}$ & I year \\
\hline Senior Clinicians & $\begin{array}{l}\text { Third or fourth year medical } \\
\text { students }\end{array}$ & $\begin{array}{l}\text { - Conduct history and physical with Junior Clinician } \\
\text { - Work with Junior Clinician to present patient to attending } \\
\text { physician, formulate an assessment and plan, and order all } \\
\text { necessary tests } \\
\text { - Follow-up with patients } \\
\text { - Attend board meetings to ensure smooth patient hand-off }\end{array}$ & 6 weeks \\
\hline Junior Clinicians & $\begin{array}{l}\text { First or second year medical } \\
\text { students }\end{array}$ & $\begin{array}{l}\text { - Conduct history and physical } \\
\text { - Present findings and work with attending physician and } \\
\text { session coordinators to formulate an assessment and plan }\end{array}$ & I night \\
\hline Attending Physician & $\begin{array}{l}\text { Faculty volunteer board } \\
\text { certified in internal medicine, } \\
\text { psychiatry, or gynecology }\end{array}$ & $\begin{array}{l}\text { - See all patients on clinic night with student medical team } \\
\text { - Advise Senior Clinicians regarding patient management } \\
\text { - Approve all clinical decisions on clinic night }\end{array}$ & I night \\
\hline
\end{tabular}

donations and grants in addition to in-kind donations from the Weill Cornell Physicians Organization, Weill Cornell Internal Medicine Associates, Weill Cornell Medical College, and NewYork-Presbyterian Hospital.

Patients are seen every Monday from 5-8 PM in clinical space that is donated by the Weill Cornell Internal Medicine Associates, the adult ambulatory care practice for attendings and Internal Medicine residents. Each patient is seen by a team of students consisting of a Junior Clinician, a first or second year student, and a Senior Clinician, a third or fourth year student, under the supervision of a licensed physician volunteer. The responsibilities of this supervising physician are to discuss and examine each patient with the medical students and develop a plan of action. Supervising physicians volunteer their time at the WCCC and must be a practicing physician and a faculty member at the Medical College. In addition, on a weekly basis, all patients are reviewed with the Faculty Medical Director to discuss patient follow-up and review the laboratory data of patients who were seen.
In 2009, the EHR system EpicCare (Epic Systems Corporation, Verona, WI, USA) was introduced into the WCCC. This provided an opportunity to reflect on the clinic practices and adopt different models of health care delivery that would maximize the use of an EHR. The PCMH model was considered because of its potential to provide students with exposure to comprehensive patient care, give them an opportunity to assume different roles as providers, and allow them to participate in interdisciplinary teams.

\section{Tenets of the PCMH}

\section{Students assume the role of the personal physician}

In a $\mathrm{PCMH}$, each patient has an ongoing relationship with a personal physician who provides continuous and comprehensive care ${ }^{13}$ (Table 2). The physician coordinates communication between members of the health care team and establishes relationships with administrative staff and outside consultants. In an effort to provide students at the WCCC with the opportunity to take on the role of a lead physician, 
Table 2 Incorporation of the principles of the patient-centered medical home into the Weill Cornell Community Clinic (New York, NY, USA) practice

\begin{tabular}{|c|c|}
\hline Components of the PCMH & Implementation within the WCCC \\
\hline $\begin{array}{l}\text { A personal physician within a physician- } \\
\text { directed medical practice }\end{array}$ & $\begin{array}{l}\text { - Clinical Directors oversee patient care for a full year } \\
\text { - Senior Clinicians act as primary care providers for } 6 \text { week blocks } \\
\text { - The Continuity of Care Program matches medical students with patients } \\
\text { - Board and directors meet weekly with Senior Clinicians to discuss all patients seen during the } \\
\text { week and care is reviewed as a team } \\
\text { - Policies and practices are discussed as a board }\end{array}$ \\
\hline $\begin{array}{l}\text { Whole-person orientation } \\
\text { and integrated care }\end{array}$ & $\begin{array}{l}\text { - All new patients receive psychosocial screening and evaluation for insurance eligibility; this is } \\
\text { repeated annually } \\
\text { - WCCC encourages regular appointments for health care maintenance by scheduling follow-up } \\
\text { care at the end of an appointment } \\
\text { - In-house women's health and mental health nights occur every } 3 \text { weeks } \\
\text { - Agreements with various specialists for low-cost referrals paid for by the WCCC }\end{array}$ \\
\hline Quality and safety & $\begin{array}{l}\text { - Adoption of EpicCare (Epic Systems Corporation,Verona,WI, USA) for EHR } \\
\text { - Health care maintenance lists with screenings and vaccinations are created for each patient at } \\
\text { the beginning of a clinic night to encourage appropriate preventative care } \\
\text { - Measurement made of health care provider hand-washing compliance } \\
\text { - Nightly checklist ensures all patient needs are met before leaving clinic } \\
\text { - Clinical operations are updated annually to ensure continuity during annual board transition }\end{array}$ \\
\hline Enhanced access & $\begin{array}{l}\text { - Patients can contact the clinic via phone or email, with messages rapidly triaged by the clinical } \\
\text { directors to ensure appropriate and timely follow-up }\end{array}$ \\
\hline
\end{tabular}

Abbreviations: EHR, electronic health records; PCMH, patient-centered medical home; WCCC, Weill Cornell Community Clinic.

third and fourth year students rotate through the WCCC for 6 weeks as part of their primary care clerkship and take on the responsibilities of the personal physician while directing the patient care team. These Senior Clinicians continue to follow the patients after each clinical session and ensure that all necessary tests and referrals are completed. The Senior Clinician also becomes the patient's advocate, helping to fill out necessary forms for social services and making sure the patient sees necessary service providers, such as referred specialists and social workers.

In order to ensure a seamless transition and patient hand-off, each outgoing Senior Clinician provides detailed information about the patient and describes any outstanding tests, referrals, or procedures that are pending to the Clinical Directors. This helps to promote a smooth transition of care when new Senior Clinicians rotate through the WCCC. The Medical Faculty Director also ensures that new students joining the WCCC are aware of pertinent outstanding patient issues.

In an attempt to meet the high level of interest among the preclinical students, Junior Clinicians sign up for individual nights rather than blocks of time, as with the Senior Clinicians. Thus, a limitation of the nature of such a studentrun free clinic can be a lack of continuity as volunteers come and go. In order to provide the opportunity for preclinical students to be involved in the long-term care of a patient, the Continuity of Care Program was piloted. This pilot project was designed to provide additional experience in communicating with patients and their families and to provide students with first-hand experience of the after visit care process. Each student in the program is paired with a patient and attends all of their appointments throughout the year, serving as Junior Clinician in those sessions. They also are involved in follow-up care - calling the patient with results and working to schedule any necessary referrals. This gives greater continuity for both student and patient.

\section{Caring for the whole person}

In the PCMH model, there is an integrated and whole-person orientation to care. The personal physician attends to all of the patient's health care needs and assumes responsibility for coordinating services with other professionals or organizations. This requires integrating all elements of a complex health system, extending from within the medical practice to various consultants, ancillary services, and community resources. ${ }^{13}$ Students in the WCCC learn to coordinate health care services for patients to address both their psychosocial and their medical needs. For example, a review of patient requests identified a need for mental health and gynecological services. In response, the WCCC developed a mental health clinic night for patients requiring psychosocial and mental health care, as well as a women's health clinic.

Despite these additions, patients needed additional social services. This posed a challenge for students, as they were 
not familiar with the breadth of social services that were available to patients. Therefore, the WCCC partnered with the Silberman School of Social Work at Hunter College (New York, NY, USA) to facilitate enrollment into health insurance plans and access to social services. The WCCC thus became a service-learning program for both the WCCC medical students and the Silberman School social work students. In collaboration with the social work students, who are supervised by a licensed social worker, the medical students compiled a list of social services that direct patients to resources such as housing, insurance, access to medication, and nutrition.

\section{Students learn to develop effective systems of communication}

Health care that is provided within a PCMH offers enhanced access to care through systems such as open scheduling, expanded hours, and alternative methods of communication. ${ }^{14}$ Despite the WCCC's limited weekly hours, the clinic maintains accessibility through electronic and telephonic communication. In order to provide enhanced access to patients and maintain effective communication, the students use an electronic inbox and voicemail system to triage patient concerns, which is monitored at least daily by the Clinical Directors. Patients can use this system to schedule appointments or make requests for referrals. Patients can also request new appointments through the WCCC's website. All telephone interactions with patients are documented in the patient's EHR and discussed with the Faculty Medical Director.

\section{Students learn to assess quality assurance and risk management}

In the PCMH model, creating systems for documenting and monitoring patient outcomes and establishing reliable systems of communication are essential components to ensuring quality of care and risk management. ${ }^{15,16}$ Students who volunteer in the WCCC receive training on using EHR to conduct quality assurance checks on patients. Students worked with the information technology team at the Medical College and adopted an existing EHR system - EpicCare - to collect and maintain patient data. All students on the WCCC board receive training and secure passwords, granting them access to patient records. This EHR provides a mechanism for collecting patient clinical data, documenting notes that can be reviewed by the supervising attending and the Faculty Medical Director, processing referrals, and documenting the exchange of information with patients. All patient calls are documented in the EHR. This EHR provides a unique opportunity to teach students about proper documentation, how to query their own patient panels, and how to collect data on quality assurance and risk management. The EHR also provides patients secure access to their test results via the Internet.

At the WCCC, students have established quality assurance and patient safety initiatives, designing a four-part quality tracking and improvement campaign. In line with the holistic orientation of a PCMH, the WCCC improves preventive care through distribution of a health care maintenance list that includes age-appropriate screenings and vaccinations. Students then do follow-up with patients regarding these measures at every clinic session. Secondly, there is a focus on improving outcomes by tracking chronic disease and preventive measures with a patient dashboard generated by the EHR. As part of a hospital-wide initiative, they also measure health care provider hand-washing compliance through patient surveys completed at the end of the appointment. Finally, students have instituted a nightly checklist that the Senior Clinicians use to ensure that important follow-up issues are not missed when patients leave. Such issues include providing the patient with a follow-up plan, processing referrals, and establishing a means of contacting patients after the visit.

As a component of tracking the quality of the experience, the student board of the WCCC received Institutional Review Board approval to perform a chart review and to survey both students and patients. For the year of July 2011 to June 2012, the EHR was interrogated to investigate patient demographics and the most common diagnoses and prescribing information. During the first year of the PCMH adoption, all 174 patients were provided surveys upon arrival at the WCCC, which were submitted before leaving the clinic. The surveys consisted of nine five-point Likert scale questions about the helpfulness of various members of the clinic, including medical students, staff, and physicians; quality of care received; and overall satisfaction with the WCCC, with options ranging from poor to excellent. The survey also included questions about the patient's primary language, total number of visits to the clinic, and time spent during the visit. Descriptive statistics were calculated using SPSS ${ }^{\circledR}$ version 20 (IBM Corporation, Armonk, NY, USA).

Student satisfaction was measured in the Continuity of Care pilot project. All ten students who finished the first year in the pilot program completed a 22-question survey regarding their experience. Eight of these questions used a five-point Likert scale to query how the Continuity of Care project supplemented the medical school experience, how it had affected future medical career plans, the student's 
relationship with the patient, and overall satisfaction with the program. Students also answered open-ended questions regarding positive aspects of their experience, as well as areas for improvement. Descriptive statistics were calculated using SPSS version 20 .

\section{Results}

A review of clinic practice over a 1-year period after a $\mathrm{PCMH}$ model was adopted showed that 112 students volunteered across all 4 years of medical school, including $70 \%$ of the first year class. They were overseen by 19 licensed physician volunteers. All students were enrolled at Weill Cornell Medical College. The ten students who participated in the Continuity of Care pilot project rated their overall satisfaction of the program on a scale from one to five, with five being extremely satisfied, as 4.2 (95\% confidence interval 3.4-5.0). The degree to which they felt this experience improved their ability to care for and manage medical conditions was rated as 3.3 (95\% confidence interval 2.2-4.5) on a scale from one to five, with five being extremely improved. The degree to which this experience enhanced their medical school education was rated as 3.9 (95\% confidence interval 2.8-5.0). Common positive themes from open-ended questions included the opportunity to "follow a patient individually throughout their medical care and watch their symptoms improve", "bridging the gaps in care", and "see(ing) how helpful good medicine can be". Areas for improvement included a need for "more structured orientation", and feeling ill-equipped to provide medical advice.

Between July 2011 and June 2012, 174 patients were seen by the WCCC at 337 appointments. A review of this patient series found that $66 \%$ were women; $37 \%$ fell in the age range of 45-59 years, 26\% were aged between 25-34 years, 20\% were 60 years and older, and 14\% were between 35-44 years. English was the primary language spoken by $87 \%$ of the patients, followed by Spanish. A significant portion of patients $(87 \%)$ reported an annual income of less than $\$ 30,000$, and $17 \%$ had an income of less than $\$ 10,000$. Almost half of the patients had at least two visits in 1 year. The most common diagnoses made during the visits included management of hypertension, well woman exam, dyslipidemia, pain, depression or anxiety, diabetes, and thyroid disease.

A total of 189 medications were reimbursed, nearly two-thirds of which were for hypertension, diabetes, and dyslipidemia. Medications for management of psychiatric diagnoses accounted for $6 \%$ of the medications; antiinflammatories and medications for insomnia each accounted for $4 \%$ of the medications; and antibiotics, eye drops, and nutritional supplements made up the remainder. A total of 785 laboratory tests were ordered. The most common tests included complete blood count, glucose level, lipid level, sexually transmitted disease screening (including human immunodeficiency virus), and thyroid function test.

A total of 87 patients fully completed the satisfaction survey. Incomplete surveys were excluded. Analysis of the patient satisfaction survey found that $87 \%$ were very or extremely satisfied with the care they received in the WCCC, and $96 \%$ of the patients would recommend the WCCC to others. Patients were asked to describe the interpersonal and technical aspects of care received from poor to excellent. Overall, $80 \%$ of patients rated the helpfulness and courtesy of the students, thoroughness and competence, and communication of the treatment plan as excellent or good. The length of time spent at the clinic was rated as excellent or good by $70 \%$ of the patients.

\section{Discussion}

Given the popularity of student-run free clinics across medical schools, integrating the PCMH into these practices can address the gap in education about this health care delivery model. By incorporating tenets of the PCMH into the WCCC, $70 \%$ of first year medical students at Weill Cornell Medical College gained hands-on exposure to this practice model. Student volunteers at the WCCC participated in a breadth of activities consistent with the guidelines put forth in the Joint Principles for the Medical Education of Physicians as Preparation for Practice in the Patient-Centered Medical Home that made recommendations on key aspects of the PCMH to which students should receive exposure, such as a longitudinal experience in continuity of care, work in interdisciplinary teams, experience with the economics of health care, practice with a variety of different types of encounters, including face-to-face and telephonic and electronic messaging, and exposure to the basics of medical informatics. ${ }^{17}$ Students involved in the Continuity of Care project reported a high level of satisfaction with their experience, as seen in other studies of student involvement in student-run clinics. ${ }^{18}$

A review of patients seen at the WCCC demonstrates that they present with a breadth of medical conditions that are consistent with what is experienced at other free clinics. ${ }^{9}$ In general, patients expressed satisfaction with the care they received at the WCCC. Need for improvement was noted in the amount of time they spent waiting to see a care team at the WCCC. Longer wait times may be due in part to the greater 
time spent by first and second year students conducting the history and physical exam. In addition, after being interviewed by medical students, all patients must be seen and examined by the supervising attending, further lengthening the time of the appointment. In response to receiving this feedback, a new student volunteer position was created to focus specifically on clinic flow and ensure patients are seen in a timely manner. Despite the wait times, over $90 \%$ of patients said that they would refer others to the WCCC.

Medical schools today must prepare students to navigate the ever-changing landscape of health care. By taking primary responsibility for the day-to-day practice of the WCCC, students put themselves not only on the frontline of clinical care, but also gain exposure to systems-level practice issues. Each barrier to be overcome has served as a learning experience for the students. The most significant obstacle has been ensuring long-term stability within the medical school while maintaining the autonomy of a student-run clinic with the care of a vulnerable population as the focus. Creating stability has involved ensuring a funding stream and advocating for support from the medical school.

In order to fund the WCCC, students gained experience with fundraising by working with the alumni association, writing grants, and seeking donations from foundations to support the clinical activities. Students were responsible for allocating the budget. The funding was utilized to support patient medications, laboratory testing, and a subset of referrals for specialty care appointments. To expand the services available to patients while operating in a tight budget, the WCCC has negotiated low-cost referrals with a number of specialty clinics and pays this fee for its patients.

The student board has worked closely with the medical school administration to maintain a mutually beneficial relationship. Students give presentations about the WCCC at meetings to promote the role of the WCCC as an important educational and service learning opportunity while also working to raise awareness for the WCCC within the college and hospital. This helps to recruit new physician volunteers. To maintain a stable influx of student involvement during their clinical years, when involvement tends to taper off with the increasing demands of clerkships, the WCCC has become a required component of the primary care/family medicine clerkship. Finally, as a reflection of the college's commitment to the WCCC, the Faculty Medical Director is now supported through a separate budget provided by the Dean's office.

Given the low income of patients, students learn to address many of the social determinants of health, such as housing, insurance, and transportation. Students are further exposed to the ethical considerations of having a studentrun clinic play such a central role in the care of the indigent patient population. As discussed elsewhere, ${ }^{19}$ student-run clinics have a responsibility to put patient care first and to create a culture of professionalism with suitable physician oversight. Patient care is paramount at the WCCC, and all individuals seeking care there are screened for appropriateness with the Faculty Medical Director. Those who are too medically fragile for the WCCC to provide sufficient care are referred elsewhere in the community.

Overcoming the challenges of implementing the $\mathrm{PCMH}$ model at the WCCC has provided invaluable lessons to all students involved. The WCCC is an evolving practice, with the enduring goal of improving clinic efficiency and patient outcomes. Each class of medical students has the opportunity to contribute to the WCCC and explore novel ways to enhance the PCMH model.

\section{Limitations}

This paper has a number of limitations. Surveys of students were restricted to those involved in the Continuity of Care pilot project, with a focus on feasibility of the project and the students' perceptions. Thus, while the students self-reported feeling better equipped to treat patients after the experience, this may be the result of simply having more education overall rather than be the direct result of their experience with the WCCC. A future study is needed to compare this experience with those not involved in the project as a control group. Furthermore, there would be benefit from an expanded evaluation of the student experience, including a comparison with other components of the curriculum. Future studies will investigate whether participation with the WCCC impacts a student's career goals.

Although all patients were provided with satisfaction surveys, only a subset of these patients completed the survey, which limits generalization. Furthermore, while all patients were informed that their responses were anonymous and participation would not affect their care, these concerns may have impacted the results. There is a need to extend beyond patient satisfaction and study outcomes of care, an area that will be addressed in future studies utilizing the EHR.

\section{Conclusion}

As efforts to implement new models of health care delivery increase, so must the efforts of educators to ensure that students receive proper exposure to these models. The WCCC provides a model for how principles of the PCMH can be taught through experiential learning activities of a student-run 
free clinic. Integrating core principles of the $\mathrm{PCMH}$ into programs such as student-run free clinics can help to better prepare students to respond to health care reform changes in their own practices. The experience of the WCCC may serve as an example for how other programs can incorporate the PCMH models as part of required ambulatory care rotations and other experiential learning initiatives. As medical schools nationwide reconsider their curricula, they must also adapt to changes in health care. The student-run free clinic can provide a model for students to play a significant role and gain hands-on experience in the intricacies of health care delivery.

\section{Acknowledgments}

The authors regret to advise of the passing of Dr Anne Kastor prior to publication. This paper is dedicated to the memory of Dr Kastor for her years of service to the WCCC. The authors wish to thank Dr Alvin Mushlin and Dr Olaf Andersen, both of Weill Cornell Medical College, for their insightful editorial suggestions. The authors are grateful to the physicians and students who have volunteered in the WCCC and the patients who allowed us to participate in their care.

\section{Disclosure}

The Weill Cornell Community Clinic receives funding from Weill Cornell Physicians Organization, Weill Cornell Internal Medicine Associates, Weill Cornell Medical College, and NewYork-Presbyterian Hospital in addition to private donors. MCR previously received and JBS, and JDS receive funding from NIH MSTP grant T32GM07739 to the Weill Cornell/ Rockefeller/Sloan-Kettering Tri-Institutional MD-PhD Program. CBF was supported by Grant Number 1P60MD003421 from the National Institute on Minority Health and Health Disparities. The content of this article is solely the responsibility of the authors and does not necessarily represent the official views of the National Institutes of Health.

JBS is presently director of the WCCC; MCR and JDS were directors of the WCCC. JL and MMR were board members of the WCCC. ASK and $\mathrm{CH}$ report no conflicts of interest in this work.

This work received approval from the Weill Cornell Medical College Institutional Review Board.

\section{References}

1. Irby DM, Cooke M, O'Brien BC. Calls for reform of medical education by the Carnegie Foundation for the Advancement of Teaching: 1910 and 2010. Acad Med. 2010;85(2):220-227.

2. Backer LA. The medical home: an idea whose time has come ... again. Fam Pract Manag. 2007;14(8):38-41.

3. Stange KC, Nutting PA, Miller WL, et al. Defining and measuring the patient-centered medical home. J Gen Intern Med. 2010;25(6): 601-612.

4. Julian K, Riegels NS, Baron RB. Perspective: creating the next generation of general internists: a call for medical education reform. Acad Med. 2011;86(11):1443-1447.

5. David A, Baxley L. Education of students and residents in patient centered medical home (PCMH): preparing the way. Ann Fam Med. 2011;9(3):274-275.

6. Garr DR, Margalit R, Jameton A, Cerra FB. Commentary: educating the present and future health care workforce to provide care to populations. Acad Med. 2012;87(9):1159-1160.

7. Meah YS, Smith EL, Thomas DC. Student-run health clinic: novel arena to educate medical students on systems-based practice. Mt Sinai J Med. 2009;76(4):344-356.

8. Swartz MK. The contributions of student-run free clinics. $J$ Pediatr Health Care. 2012;26(6):397.

9. Simpson SA, Long JA. Medical student-run health clinics: important contributors to patient care and medical education. J Gen Intern Med. 2007;22(3):352-356

10. Zucker J, Gillen J, Ackrivo J, Schroeder R, Keller S. Hypertension management in a student-run free clinic: meeting national standards? Acad Med. 2011;86(2):239-245.

11. Anderson DR, Olayiwola JN. Community health centers and the patient-centered medical home: challenges and opportunities to reduce health care disparities in America. $J$ Health Care Poor Underserved. 2012;23(3):949-957.

12. Joo P, Younge R, Jones D, Hove J, Lin S, Burton W. Medical student awareness of the patient-centered medical home. Fam Med. 2011;43(10):696-701.

13. Kellerman R, Kirk L. Principles of the patient-centered medical home. Am Fam Physician. 2007;76(6):774-775.

14. Barnhart A, Lausen H, Smith T, Lopp L. Electronic health communication: an educational application for this principle of the patient-centered medical home. Fam Med. 2010;42(5):322-326.

15. Rittenhouse DR, Thom DH, Schmittdiel JA. Developing a policy-relevant research agenda for the patient-centered medical home: a focus on outcomes. J Gen Intern Med. 2010;25(6):593-600.

16. Fernald DH, Deaner N, O'Neill C, Jortberg BT, Degruy FV 3rd, Dickinson WP. Overcoming early barriers to PCMH practice improvement in family medicine residencies. Fam Med. 2011;43(7):503-509.

17. American Academies of Family Physicians; American Academy of Pediatrics; American College of Physicians; American Osteopathic Society. Joint Principles for the Medical Education of Physicians as Preparation for Practice in the Patient-Centered Medical Home. Philadelphia, PA: American College of Physicians; 2010. Available from: http://www. acponline.org/running_practice/delivery_and_payment_models/pcmh/ understanding/educ-joint-principles.pdf. Accessed July 6, 2014.

18. Bennard B, Wilson JL, Ferguson KP, Sliger C. A student-run outreach clinic for rural communities in Appalachia. Acad Med. 2004;79(7):666-671.

19. Buchanan D, Witlen R. Balancing service and education: ethical management of student-run clinics. $J$ Health Care Poor Underserved. 2006;17(3):477-485. 
Advances in Medical Education and Practice

Dovepress

\section{Publish your work in this journal}

Advances in Medical Education and Practice is an international, peerreviewed, open access journal that aims to present and publish research on Medical Education covering medical, dental, nursing and allied health care professional education. The journal covers undergraduate education, postgraduate training and continuing medical education including emerging trends and innovative models linking education, research, and health care services. The manuscript management system is completely online and includes a very quick and fair peer-review system. Visit http://www.dovepress.com/testimonials.php to read real quotes from published authors.

Submit your manuscript here: http://www.dovepress.com/advances-in-medical-education-and-practice-journal 